\title{
SOBRE O ESTADO DE EQUILÍBRIO ENTRE AS VERDADES QUE SE DIZEM E AS PALAVRAS QUE AS DIZEM: A ESTÉTICA NEORREALISTA E A BUSCA POR MODOS DE FAZER POÉTICO NA OBRA DE CARLOS DE OLIVEIRA
}

\author{
ABOUT THE STATE OF EQUILIBRIUM \\ BETWEEN THE TRUTHS THAT ARE SAID \\ AND THE WORDS THAT SAY THEM: THE \\ AESTHETICS OF NEO-REALISM AND THE \\ SEARCH FOR WAYS OF POETICAL DOING IN \\ THE WORKS OF CARLOS DE OLIVEIRA
}

\author{
Daniel Marinho Laks* \\ Alexandre Montaury Baptista Coutinho
}

\section{RESUMO}

O artigo parte das ideias de Maurice Blanchot e Ezra Pound sobre a poesia enquanto forma condensada de narrar. Assim, apresenta-se a noção de percepção estética, ligada ao visual e ao sensível, em paralelo à percepção que se faz do texto enquanto linguagem no sentido de veículo de comunicação. A partir deste duplo mecanismo de apreciação, imagético-sensível e teleológico, pretendemos discutir a maneira como o livro Cantata, de Carlos de Oliveira, marca um investimento na forma, enquanto trabalho específico do artista que se apresenta em plano polêmico à ideia de primazia do conteúdo em detrimento da forma, periodicamente afirmada como base de uma teorização ortodoxa do neorrealismo português. Assim, o presente trabalho entende o neorrealismo não apenas como um movimento estritamente literário ou artístico, ou um movimento de geração, mas como a constituição de uma problemática impulsionadora de um questionamento sistemático nos domínios da arte, da política e da cultura.

PALAVRAS-CHAVE: Carlos de Oliveira. Neorrealismo. Política poética. 


\section{ABSTRACT}

The article is based on the ideas of Marice Blanchot and Ezra Pound about the poetry as a condensed narrative form. The notion of an aesthetic perception, related to the visual and sensitive, in parallel to the perception of the text as language in the sense of communicating is presented. From this double mechanism of appreciation, imagistic-sensitive and teleological, we intend to discuss the way that the book Cantata, from Carlos de Oliveira, marks an investment in the form as an specific work of the artist that presents itself in a controversial plan to the idea of primacy of content over form, periodically affirmed as the basis of the orthodox theorization for Portuguese neo-realism. Thus, the present article understands the neo-realism not only as a strictly literary, artistic or generational movement, but as a systematic questioning on the domains of art, politics and culture.

KEYWORDS: Carlos de Oliveira. Neo-realism. Poetic politics.

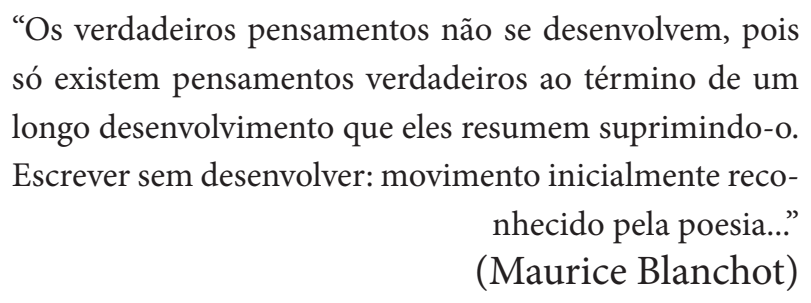

Na epigrafe acima, Maurice Blanchot reconhece na poesia o movimento de condensação de uma tese que suprime o desenvolvimento da ideia que apresenta. A poesia se desenvolve enquanto escrita na medida em que suprime, na sua própria estrutura, o desenvolvimento prosaico da ideia que resume. Esta relação entre a escrita poética e uma forma concisa e sintética de expressar determinada tese retoma um conceito específico de poesia, que credita ao desenvolvimento do que é específico do trabalho poético formal esta supressão dos possíveis desenvolvimentos da ideia que sustenta. Em $A B C$ da literatura, Ezra Pound narra o caso acontecido com o poeta inglês Basil Bunting, que, ao folhear um dicionário alemão-italiano, descobriu que a ideia de poesia como concentração é quase tão antiga quanto a língua germânica. "Dichten é o verbo alemão correspondente ao substantivo Dichtung, que significa poesia e o lexicógrafo traduziu-o pelo verbo italiano condensare, que significa condensar" (POUND, 2006, p. 44). Pound relaciona a potência de gerar desenvolvimentos múltiplos à própria forma condensada de narrar, apresentando a noção de uma percepção estética, ligada ao visual e ao sensível, em paralelo à percepção que se faz do texto enquanto linguagem, no sentido de veículo de comunicação. Assim, esse duplo mecanismo de apreciação, imagético-sensível e teleológico, seria, então, responsável pela condição inesgotável do texto poético: pode-se ler um mesmo poema incontáveis vezes, mas, a cada leitura, como um poema diferente. 
O livro Cantata, composto por uma coletânea de poemas de Carlos de Oliveira e publicado pela primeira vez em 1960, marca um período específico do "amadurecimento em público" do poeta neorrealista, que passa a atribuir um grau diferenciado de sofisticação formal à sua obra, quando comparado a poemas reconhecidos como emblemáticos de uma forma de intervenção mais imediatista, como exemplo, os poemas do livro Mãe Pobre. O poema Cruz à beira do caminho demonstra esse caráter direto de Mãe Pobre, retratando personagens despossuídos, como o caminheiro, e abordando literalmente a pobreza do ambiente rural com a ausência da colheita e a casa destelhada:

Cruz à beira do caminho

Recordo-te, caminheiro esquecido:

Eras o corpo do povo e a sua voz;

aqui jazes, aqui jazemos nós.

O milho que não colheste, a casa destelhada e a terra que não te deram são o silêncio que nos perde onde o luar e as estrelas te perderam.

E enquanto a vida nos ladrar como os cães ao rasto dos pés nus, morto da gândara, ficam estes dizeres na tua cruz. (OLIVEIRA, 2003, p. 55).

A sofisticação formal dos poemas de Cantata pode ser percebida na ausência de pontuações, permitindo diferentes leituras do texto, conforme abordaremos mais à frente:

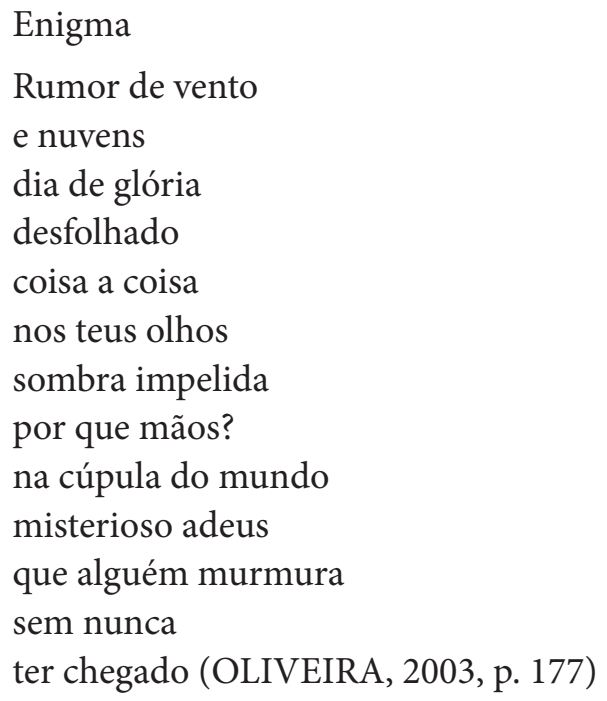

Este investimento na forma enquanto trabalho específico do artista se apresenta em plano polêmico à ideia de primazia do conteúdo em detrimento da forma, periodicamente afirmada como base de uma teorização ortodoxa do neorrealismo português. Entretanto, estudos que partem de uma matriz de pensamento que define o neorrealismo não apenas como um movimento estritamente literário ou artístico, ou um movimento de geração, mas como a constituição de uma problemática impulsionadora de 
um questionamento sistemático nos domínios da arte, da política e da cultura, estabelecem enquanto base que "a recorrente afirmação do primado do conteúdo e da arte como espelho deve ser considerada desde o início em polêmica tensão com a valorização da forma e da arte como construção" (PITA, 2002, p. 238).

A análise de alguns aspectos selecionados do trabalho poético de Carlos de Oliveira, presente neste ensaio, constrói-se a partir desse entendimento ampliado do conceito de neorrealismo, entendendo o investimento diferenciado no trabalho formal, que se estabelece na obra de Carlos de Oliveira a partir de Cantata, não como um afastamento do neorrealismo ou do marxismo como base de formulação teórica e estética, mas sim como reflexo de um amadurecimento do poeta e da reconfiguração das conjunturas estabelecidas pelas transformações sociais, culturais e políticas transcorridas em Portugal e na Europa de maneira geral, da década de 1940 até a publicação de Cantata, em 1960, e obras posteriores. Se os livros Mãe Pobre, publicado pela primeira vez em 1945, e Descida aos infernos, de 1949, apresentam uma escolha temática mais facilmente relacionável às chamadas formulações ortodoxas do neorrealismo, como a reelaboração de formas populares e um maior investimento na comunicabilidade direta, Cantata marca um momento de sofisticação do domínio da técnica enquanto paradigma da práxis (PITA, 2002, p. 225) na poética de Carlos de Oliveira. Entretanto, essas alterações, que se expressam enquanto possibilidades do fazer poético, não podem ser analisadas isoladamente das transformações no domínio das artes e da cultura vivenciadas nos quinze anos que separam as obras mencionadas.

A convicção de que a arte gera comunidade está disponível desde meados dos anos trinta. Os jovens intelectuais, em processo de organização e de tomada de consciência desencadeado pelas implicações sociais, políticas e artísticas da crise de 1929 e fortemente acelerado com a Guerra Civil da Espanha, admitiam este paradigma apriori, ainda no plano da sua pré-compreensão. Para esses jovens intelectuais e, posteriormente, para a formação e consolidação do neorrealismo, a arte não é uma questão derivada, na medida em que é o específico da arte que mobiliza politicamente esses jovens intelectuais enquanto artistas.

Em 1937, Mario Dionísio lança a hipótese de que a arte, mesmo a mais subjetiva, partilhava do desígnio de toda arte, que é, em última análise, revelar o homem como elemento do real. Apoiando-se nas considerações traçadas por Marcel Gromaire, Dionísio postula que: “o real não é somente o que é do domínio da nossa mão, do domínio da nossa vista, é também o que é do domínio do nosso espírito e o que ainda não é do domínio do nosso espírito" (DIONÍSIO, 1973, p. 94). Dessa forma, o real é entendido não somente como o que se pode mostrar, o que se pode designar e, portanto, reconhecer; é também o que, por ainda não pertencer ao domínio do presente, deve ser antecipado e, através dessa antecipação, constituir-se em correspondente de um autêntico discurso de revelação ou 
descoberta. Esse duplo entendimento do conceito de real instaura a polêmica no âmago da elaboração de uma estética marxista em Portugal, onde, por um lado, cunha-se um realismo que torne visível um real contraditório em si mesmo, "sendo o neo a consciência do caráter histórico e social da contradição” (PITA, 2002, p. 236), e, por outro, uma estrutura narrativa realista que revele mesmo o que ainda não é da ordem do visível, ou seja, uma estrutura realista que revele uma função gnosiológica da arte.

É possível que as duas explanações do conceito de real pudessem ter sido consideradas sinônimas na época; entretanto, a revelação deste $o$ que ainda não é afasta o neorrealismo de todo o paradigma da visão apreendida como comunicabilidade imediata, exigindo procedimentos formais diferenciados. O imediatismo da comunicação é, portanto, diretamente proporcional à transparência das formas que realizam a comunicação. Assim, por um lado, o real ou a vida que na arte se exprimem contêm uma possibilidade de relação imediata; por outro lado, a especificidade do trabalho artístico que se traduz na existência de uma mediação irredutível, "que é o lugar da reconstrução do mundo real de que o artista tem experiência direta no mundo real que, na tela, o artista faz aparecer" (PITA, 2002, p. 236).

Os contornos mais agudos e definitivos do conflito e da polêmica interna do neorrealismo foram traçados a partir de entendimentos equivocados das relações entre arte e cultura dentro do universo marxista. $\mathrm{Ou}$ seja, entre o trabalho da imaginação e a construção de uma mundividência. A arte, sendo espaço de trabalho da imaginação, funciona num plano virtual. A cultura, enquanto geradora de sentido, dá consequência política à reconfiguração ideológica. Sem a cultura, os princípios doutrinários da viragem política permanecem somente num plano virtual. É através da cultura, do devir social que é próprio da cultura, que se expressa o que, até então, era virtual.

Antônio Gramsci (1977), no artigo intitulado Marinetti Revolucionário?, faz uma análise da utilidade das ideias, que na sua contemporaneidade estava associada ao futurismo, para uma sociedade proletária. No artigo, ele discute a serventia de algumas proposições futuristas e atitudes perante a arte para um ideário de revolução comunista. Para Gramsci, existe uma imprevisibilidade na produção cultural de uma sociedade que ainda não se concretizou. Gramsci admite como evidente que em uma sociedade proletária existirão "uma poesia, uma pintura, uma música características da civilização proletária, florescência e ornamento da organização proletária" (GRAMSCI, 1977, p. 246). Nesse sentido, antes de se lançarem as bases para a representação das formas culturais nessa nova sociedade, seria necessária a destruição das antigas formas culturais. Entretanto, a destruição, no campo cultural, não carrega o mesmo significado que no campo econômico. A destruição, no campo econômico, significaria a privação de produtos materiais fundamentais para a manutenção e o desenvolvimento das sociedades. No campo da cultura, a destruição significaria a ruptura com "hierarquias espirituais, preconceitos, ídolos, tra- 
dições rígidas, significa não ter medo das novidades e das audácias, não ter medo dos monstros, não crer que o mundo acaba se um operário comete um erro de gramática (...)” (GRAMSCI, 1977, p. 247).

A partir desta ideia da necessidade da destruição das antigas hierarquias às quais a arte estava submetida como necessidade fundamental para se criar as bases de edificação de novas formas de representação, Gramsci discorre sobre o papel desempenhado pelos futuristas para se atingir este objetivo. Para ele, o futurismo foi pioneiro no desempenho da missão de destruir, no campo da cultura, as hierarquias relacionadas à ordem burguesa. Gramsci, nesse sentido, elogia a autoconsciência histórica dos futuristas de pressentirem que a nova época que surgia necessitava de novas formas de expressão, que seguissem a dinâmica das novas formas de organização social: "tiveram a concepção nítida e clara que a nossa época, a época da grande indústria, da grande cidade operária, da vida intensa e tumultuosa, devia ter novas formas de arte, de filosofia, de costume, de linguagem" (GRAMSCI, 1977, p. 247). Nesse sentido, os futuristas teriam sido revolucionários no campo da cultura e lançado as bases de um processo de ruptura com os dispositivos da sociedade burguesa que também deveria ser seguido pelos socialistas na construção de uma sociedade proletária.

António Pedro Pita (2012), na conferência intitulada "Mudar a vida" precisa da arte?, propõe uma contextualização histórica para o artigo de Gramsci. Pita relembra que Gramsci escreve o artigo nos inícios de 1921, ou seja, menos de quatro anos após o início da revolução russa e quase doze anos depois da publicação do Manifesto Futurista. Segundo Pita, esses dois eventos podem ser pensados em conjunto como responsáveis por um devir paradoxal. Em seu artigo, Gramsci parte da premissa de que, antes da primeira guerra mundial, havia uma simpatia entre grupos operários e futuristas:

Muitos grupos operários viram com simpatia (antes da primeira guerra europeia) o futurismo. Aconteceu muitas vezes (antes da guerra) que grupos de operários defendessem os futuristas das agressões intriguistas de literatos e artistas de carreira (GRAMSCI, 1977, p. 245).

Segundo Pita, a referência às circunstâncias nas quais essa simpatia se desenvolveu é um ponto central no entendimento da questão suscitada por Gramsci. Pita propõe que o limite temporal da simpatia entre futuristas e operários não seria a "primeira guerra europeia", mas sim a revolução russa. Segundo ele, a revolução russa significava que um dos desenlaces possíveis da crise que abalava as estruturas da sociedade burguesa no século XX se manifestava enquanto crise social. Nesse sentido, seria a revolução russa, e não a primeira guerra europeia, a coordenada essencial para a composição de um "imaginário de revolução", que gerava uma conjuntura de mudança nas formas de vida, de alteração na autoconsciência histórica. Nesse sentido, "mudar a vida é sobretudo mudar de tempo" (PITA, 2012, p. 3). Entretanto, as considerações traçadas por Gramsci so- 
bre o significado de destruição na arte tiveram muito pouco ou nenhum acolhimento pelos teóricos e realizadores do neorrealismo no momento.

Se o espaço relativo ao neorrealismo é marcado, desde o início, por conflitos e polêmicas, estas permanecem internas e silenciadas ao longo de toda a década de 1940, devido à sobredeterminação política pelas condições do antifascismo. O movimento cultural formado por uma perspectiva marxista desenvolve-se em Portugal com a reorganização do Partido Comunista Português (PCP) em 1940-41, a disseminação dessas ideias marxistas e uma progressiva influência política e social. Esses pontos são momentos de uma estratégia de formação de uma frente única antifascista que já havia sido sobredeterminada pelo movimento comunista internacional no VII Congresso da Internacional Comunista de 1935. Dessa forma, qualquer controvérsia que pusesse em perigo o êxito político da estratégia da frente única era rapidamente silenciada.

O caráter mais direto e doutrinário de livros como Mãe Pobre, Colheita Perdida e Descida aos Infernos, assim, não estaria relacionado a uma homogeneidade artística e teórica do neorrealismo, que cada vez mais estudos têm comprovado inexistente, mas a uma fase específica no amadurecimento de um poeta e à própria tensão doutrinária que vai circunscrever-se durante vários anos ao âmbito da cultura, devido ao panorama da Europa e, especialmente, de Portugal na década de 40: os anos de batalha da Segunda Guerra Mundial com a neutralidade portuguesa, mas depois com a consequente derrota dos Nazistas na Alemanha e a perspectiva de transformações em Portugal frente à derrota dos fascismos na Europa e o restabelecimento dos sistemas liberais, o entusiasmo gerado com a fundação do Movimento de Unidade Democrática (MUD) e MUD juvenil (MUDJ) em 1945 e as expectativas democratizantes geradas pela candidatura à Presidência da República do General Norton de Matos em 1949.

Carlos de Oliveira publica Mãe Pobre, Colheita Perdida e Descida aos Infernos com vinte e quatro, vinte e oito e vinte e nove anos de idade, respectivamente, frente a uma conjuntura sociopolítica e cultural que inspirava uma atitude de atuação mais direta na luta por conquistas sociais e políticas em Portugal. Entretanto, apesar de reconhecer em algumas obras um chamado mais direto para a conscientização política, mesmo os poemas mais conteudistas dos livros da década de quarenta apresentam uma clara preocupação com a forma e com o trabalho da linguagem. Além disso, a poética de Carlos de Oliveira se afasta em muito da positividade da experiência e do tom futurizante derivado do reconhecimento do homem enquanto sujeito da história, tornando muito difícil afirmar, após análise sistemática, em qualquer momento da sua obra, um privilégio do conteúdo em detrimento dos aspectos formais, e uma homogeneidade entre a sua produção e outros textos da época, também reconhecidos como neorrealistas. O poema 4, de Mãe Pobre, e o poema 16, de Descida aos Infernos, são aqui apresentados como exemplos destes aspectos na obra de Carlos de Oliveira: 
Aço na forja dos dicionários, as palavras são feitas de aspereza:

o primeiro vestígio da beleza

é a cólera dos versos necessários (OLIVEIRA, 2003, p.48).

16

Juro pelos meus olhos

que te venho pedir

o apocalipse da esperança:

a carícia da peste,

as patas dum cavalo,

o incêndio duma lança;

os dentes arrancados

à cárie da fome;

a dolorosa guerra

nos túmulos dos mortos

e dos vivos sem nome (OLIVEIRA, 2003, p.106).

A década de 1950 altera drasticamente o panorama relativo às bases de organização interna do neorrealismo e às próprias conjunturas sociopolíticas do mundo, às quais a arte realista invariavelmente responde. Em Portugal, a prisão de diretores importantes e militantes do PCP, como Álvaro Cunhal e Militão Ribeiro, a partir de 1949, desestabilizou o aparelho de suporte da clandestinidade neorrealista. Fora de Portugal, o desenvolvimento da Guerra Fria, o Plano Marshall, a proclamação da República Popular da China, a morte de Stalin e a revelação do sistema de campos de concentração soviético fragilizam drasticamente o fundamento marxista-leninista do socialismo real como expressão necessária do ideário marxista. Somado a isso estava o fim da estratégia da frente única antifascista, com a polarização política entre comunistas e não comunistas. No plano artístico, a produção surrealista, que se inicia em Portugal a partir de 1947, contribui para estabelecer a arte não como um recurso de embelezamento, mas como verdadeiramente o modo através do qual o real se revela, torna-se visível. Assim, a arte funcionaria como uma modalidade específica de conhecimento.

Além disso, os ideários de um Novo-Romance Português que incorpora uma solução abstracionista derivada do pensamento francês repõem o importante tema da comunicabilidade como problema, que já figurava na arte de cunho social e nos primórdios da formação do grupo neorrealista, desde a influência dos trabalhos de Maiakovski, como O Incompreensível para as Massas, da década de 1920. Todas essas alterações nas conjunturas internacionais e portuguesas retiram a polêmica do seu estado latente no ambiente interno do neorrealismo, fazendo com que as contra- 
dições se tornassem públicas e subissem para o primeiro plano, mostrando toda a sua eficácia. As considerações de Carlos de Oliveira na década de 1950 sobre a arte enquanto mediação irredutível se afastam mais ainda das orientações dos partidários do primado do conteúdo e da aspiração à comunicabilidade imediata: "o nosso ofício é escolher as palavras, utilizá-las no momento próprio, atenuá-las, engrandecê-las - dominá-las. E as palavras são a língua, a Língua e o Povo, é o legado culto de toda uma literatura" (OLIVEIRA apud PITA, 2002, p. 240). É através das palavras, sons e cores que o artista cria as formas e produz os caminhos para a beleza, já que "a beleza exige um permanente estado de equilíbrio entre as verdades que se dizem e as palavras que as dizem" (OLIVEIRA apud PITA, 2002, p. 240).

No artigo Resistência da poesia/Resistência na poesia, Rosa Maria Martelo qualifica os poemas do livro Cantata como portadores "de uma limpidez formal notável, rarefeitos e concisos, esses poemas eram, sem dúvida, diferentes de algumas das mais emblemáticas composições neorrealistas assinadas por Carlos de Oliveira" (MARTELO, 2012, p. 37). Essa condensação de ideias possíveis expressa na forma concisa e rarefeita dos versos de Cantata evidencia-se também pela extrema redução no uso das pontuações, permitindo diferentes leituras e imagens a partir do mesmo poema, dependendo das pausas que o leitor faz. Essa aglutinação de imagens e sentidos parece funcionar dentro do mecanismo de apreciação imagético-sensível e teleológico suscitado por Pound em seu $A B C$ da Literatu$\mathrm{ra}$. Entretanto, essa crescente condensação de sentidos dos versos na obra de Carlos de Oliveira parece também estar relacionada a uma incorporação do conceito de falta na estrutura de sua poética, como já apontado por Rosa Maria Martelo:

Os poemas recolhidos neste livro já não propunham um contrato de leitura realista, já não criavam qualquer ilusão de transparência discursiva, já não pugnavam explicitamente por justiça. Eram textos rarefeitos, de versos curtos e abruptos, escritos com recurso frequente a um vocabulário de raiz concreta, no qual o poeta corporizava um pensamento assumidamente materialista e dialético. Textos que obrigavam o leitor a deter-se nas características formais, e nos quais a "carência de tudo" - observada por Carlos de Oliveira nos desapossados de terra se transformara em forma, estilo - "tatuagem", para usar uma imagem do poeta - do mesmo modo que a carência, a precariedade e a brevidade que observara na vida dos seres humanos vitimizados por outros seres humanos se tinha transformado em discurso breve, rarefeito, precário (MARTELO, 2012, p. 38).

A incorporação de conceitos norteadores do marxismo como o materialismo e a dialética como modelo do devir histórico à estrutura poética dos versos de Carlos de Oliveira a partir de Cantata apresenta-se como um modo de fazer possível, uma poética dentro do universo neorrealista. Nesse ponto, a poética de Carlos de Oliveira assume um diálogo 
com a tradição da poesia moderna que seria marcante na poesia portuguesa da década de 1960. A criação dessa possibilidade de caminho neorrealista que incorpora os temas anteriores à forma, ao tratamento da linguagem enquanto matéria, suscetível de demonstrar o mundo sem ter que exemplificar explicitamente, amplia o panorama neorrealista para abranger a posição autonômica da obra de arte, reivindicada anteriormente pelos modernistas, "encarando os poemas como criações discursivas que são em si mesmas atos de resistência, independentemente da necessidade de explicitações de caráter ideológico ou de tomadas de posição políticas explícitas" (MARTELO, 2012, p. 39). O investimento na condensação da linguagem e na metáfora enquanto maneira de "transfigurar a realidade" para gerar uma forma de repactualização do real funciona na "luta contra o imobilismo e contra a tola veneração do que está” (CRUZ, 1963, p. 17- 24), como uma forma de desestabilizar as noções instituídas de verdade. Esta poética de transfiguração apresenta uma concepção específica da relação entre a arte e o real, que se aproxima de algumas das considerações traçadas por Bento de Jesus Caraça, na conferência Uma arte de via reduzida e uma arte de via longa.

Caraça postula que é possível gerar comunidade indo ao encontro do estado atual dos conhecimentos, das sensibilidades e das expectativas das pessoas e criar "uma arte de via reduzida, de segundo plano, com grande abundância da literatura de cordel e de fadinho bem medido à torneira da telefonia" (CARAÇA apud PITA, 2002, p. 253). Esta arte reforçaria o comum atual, adormeceria os sentidos, esta via da arte representaria uma evasão do real. Mas é possível gerar comunidade por outra via, mais exigente. A "arte de via reduzida" é dispersiva, alimenta as singularidades e as distâncias porque toca o sentimento dos homens num plano imediatista que dispensa o trabalho da mediação racional. Mas dispensar o trabalho da mediação racional significa desvalorizar o trabalho específico da arte o trabalho da linguagem e a importância da forma. Ao entender-se a arte engajada, e, portanto, o neorrealismo literário como uma estética que deve "contribuir para que se atinja um estado maior de justiça social" (TORRES, 1977, p. 44), atribuí-se à arte a possibilidade de tornar-se elemento fundamental no imperativo "mudar de vida e transformar o mundo". Nesse ponto, consideram-se dois níveis de eficácia da obra de arte na formação da subjetividade: 1) A obra de arte torna consciente, ou seja, a obra de arte faz a mediação entre a realidade conhecida e a experiência comum. 2) A obra de arte torna conhecido, ou seja, a obra de arte funciona como mediação entre a experiência comum e uma experiência ainda não conhecida do real, fazendo ver aquilo que antes dela e sem ela não era da ordem do visível. A ideia de trabalho poético que se desenvolve a partir de Cantata relaciona-se com o entendimento de arte realista enquanto aquela que torna conhecido, e esse processo de apresentação desse novo que é capaz de emancipar os homens requer uma receptividade ativa por parte do leitor, o que torna a sua compreensão mais difícil. 
Em conclusão, a partir de Cantata Carlos de Oliveira lança mão de uma poética que incorpora a falta percebida na vida dos desapossados à estrutura dos versos, a fim de, dessa forma, gerar, no âmbito da cultura, uma mundividência da luta de classes e das desigualdades sociais que precisam ser superadas. Esta incidência do funcionamento do real baseada na luta de classes e proveniente do materialismo histórico e, portanto, de teorização marxista, opõe-se ferrenhamente ao corporativismo encarnado pelo Estado Novo Português, com seu discurso de honra na pobreza e apaziguamento das diferenças através de mecanismos truculentos de controle. Entendendo o marxismo como estética, a poética de transfiguração da realidade proposta por Carlos de Oliveira a partir da década de 1960 permanece como um distinto exemplo das possibilidades do fazer poético que abrangem o neorrealismo português, dependendo do entendimento do que é da ordem do real. A dupla interpretação do conceito de real da hipótese de Mário Dionísio, apoiado nas considerações de Marcel Gromaire, e os diferentes modos de fazer arte, teorizados por Bento de Jesus Caraça, funcionam como evidências da instauração do conflito e da polêmica no interior do "código genético do neorrealismo" desde os seus primórdios.

\section{REFERÊNCIAS BIBLIOGRÁFICAS}

CRUZ, Gastão. Alguns problemas do Realismo. Diário de Lisboa, Lisboa, 27 jun. 1963. Suplemento vida artística e literária, pp 17 e 24.

DIONÍSIO, Mario. A paleta e o mundo, I, Publicações Europa-América, Mem Martins, 1973.

GRAMSCI, Antônio. Marinetti Revolucionário?. In: Escritos Políticos, vol. II, Lisboa: Seara Nova, 1977. 245- 247.

MARTELO, Rosa Maria. Resistência da poesia/resistência na poesia. Tropelías. Revista de Teoría de la Literatura y Literatura comparada, $\mathrm{n}^{\circ} 18$, 2012.

OlIVEIRA, Carlos. Cantata. In: OLIVEIRA, Carlos. Trabalho Poético. Lisboa: Assírio \& Alvim, 2003. 157-178.

OlIVEIRA, Carlos. Colheita Perdida. In: OLIVEIRA, Carlos. Trabalho Poético. Lisboa: Assírio \& Alvim, 2003. 59-87.

OLIVEIRA, Carlos. Descida aos Infernos. In: OLIVEIRA, Carlos. Trabalho Poético. Lisboa: Assírio \& Alvim, 2003. 91-110.

OLIVEIRA, Carlos. Mãe Pobre. In: OLIVEIRA, Carlos. Trabalho Poético. Lisboa: Assírio \& Alvim, 2003. 31-56.

POUND, Ezra. ABC da literatura. $11^{\text {a }}$ edição. São Paulo: Cultrix, 2006.

PITA, António Pedro. Mudar a vida" Precisa da Arte?. Conferência pronunciada na Universidade Federal de Santa Catarina em 21 de maio de 2012. 
PITA. António Pedro. Conflito e unidade no Neo-realismo Português. Porto: campo das letras, 2002.

TORRES, Alexandre Pinheiro. O movimento neo-realista em Portugal na sua primeira fase. Lisboa: Livraria Bertrand, 1977.

Recebido para publicação em 02/04/2015

Aprovado em 22/08/2015

\section{NOTAS}

* Daniel Laks possui graduação em Educação Física pela Universidade Estácio de Sá (2005), mestrado em Ciências Biológicas (Fisiologia) pela Universidade Federal do Rio de Janeiro (2008) e mestrado em Letras pela Pontifícia Universidade Católica do Rio de Janeiro (2011). Atualmente é aluno do programa de doutorado Literatura, Cultura e Contemporaneidade na Pontifícia Universidade Católica do Rio de Janeiro e assistente de pesquisa - Catedra Padre Antônio Vieira de Estudos Portugueses- PUC-Rio.

Alexandre Montaury Baptista Coutinho é Professor Adjunto 2 da Pontifícia Universidade Católica do Rio de Janeiro. Atua no Quadro Principal do Programa de Pós-Graduação em Literatura, Cultura e Contemporaneidade. Pesquisador do CNPq (PQ-2) e da FAPERJ (JCNE-2012). Coordena projetos de pesquisa centrados no estudo das literaturas de língua portuguesa, com ênfase na literatura portuguesa e nas literaturas africanas de língua portuguesa. 